\title{
VULNERABILIDADE SOCIAL E SOLIDARIEDADE ENTRE JOVENS: JARDIM ÂNGELA E JARDIM SÃO LUÍS
}

\author{
VULNERABILIDAD SOCIAL Y SOLIDARIDAD ENTRE JÓVENES: \\ JARDIM ÂNGELA Y JARDIM SÃO LUÍS \\ SOCIAL VULNERABILITY AND SOLIDARITY AMONG YOUNG \\ PEOPLE: JARDIM ÂNGELA AND JARDIM SÃO LUÍS
}

\section{Tiago Corbisier Matheus ${ }^{1}$}

${ }^{1}$ Fundação Getúlio Vargas, São Paulo/SP, Brasil

\begin{abstract}
RESUMO: Este é um estudo exploratório sobre a vulnerabilidade social da juventude dos bairros Jardim Ângela e Jardim São Luís, na zona sul da capital paulistana. Por meio de pesquisa participante e conversas com jovens, educadores e agentes sociais da região, ficou realçada a precariedade de recursos públicos empregados nessa região. Os jovens, por sua condição social estratégica, mostram-se particularmente premidos pelos problemas locais e reagem conforme suas possibilidades e recursos disponíveis. As instituições voltadas para a educação, por sua vez, têm propostas e políticas de gestão heterogêneas, carecendo de maior articulação com seus pares locais, o que limita seu potencial de ação. Por outro lado, nota-se como traço entre moradores a formação de laços de solidariedade na rede de relações da comunidade local, o que constitui importante recurso para a construção de políticas públicas voltadas ao combate à desigualdade social local.
\end{abstract}

PALAVRAS-CHAVE: Juventude; Vulnerabilidade; Solidariedade.

RESUMEN: Este es un estudio exploratorio sobre la vulnerabilidad social de la juventud de los barrios Jardim Ângela y Jardim São Luís, en la zona Sur de la capital de São Paulo. Por intermedio de una encuesta participante y de diálogos con jóvenes, educadores y agentes sociales de la región, se resaltó la precariedad de recursos públicos empleados en aquella región. Los jóvenes, por su condición social estratégica, se ven particularmente presionados por los problemas locales y reaccionan según sus posibilidades y recursos disponibles. Las instituciones volcadas a la educación, a su vez, tienen propuestas y políticas de gestión heterogéneas, sin articulación con sus pares locales, lo que limita su potencial de acción. De otra parte, se nota como un trazo común entre vecinos la formación de lazos de solidaridad en la red de relaciones de la comunidad local, lo que constituye importante recurso para la construcción de políticas públicas volcadas al combate a la desigualdad social local.

PALABRAS CLAVE: Juventud; Vulnerabilidad; Solidaridad.

ABSTRACT: The study explores the social vulnerability of young people living in the Jardim Ângela and Jardim São Luís neighborhoods, located in the southern region of the capital city of São Paulo. A participating survey and conversation with local young people, educators, and social workers highlighted the precariousness of public resources employed in this region. The youth, owing to their strategic social condition, are particularly vulnerable to local problems and react according to their possibilities and available resources. Educational institutions, in turn, have heterogeneous proposals and management policies, lacking better articulation with local counterparts thus limiting their action potential. On the other hand, the formation of solidarity bonds among residents is noted on the network of relations of the local community, which is an important resource for the construction of public policies intended to fight social inequalities in the region.

KEYWORDS: Youth; Vulnerability; Solidarity. 


\section{Introdução}

Esta pesquisa tem como foco a condição de vida da juventude habitante da zona sul da cidade de São Paulo, especificamente, do Jardim Ângela e do Jardim São Luís. Busca conhecer a condição dos jovens moradores da região, suas aspirações, conflitos e impasses, tendo em vista a condição em que vivem e os recursos disponíveis. Este estudo é parte da pesquisa sobre vulnerabilidades urbanas na Estação de Pesquisa em M'Boi Mirim, que envolveu outros pesquisadores do Centro de Pesquisa em Administração Pública e Governo, da Fundação Getúlio Vargas (CEAPG), a fim de formar um conjunto capaz de analisar a condição de vulnerabilidade dos habitantes da região em sua complexidade, nos diferentes aspectos que a compõem.

Adotou-se aqui a pesquisa participante como método, para que a experiência dos pesquisadores fosse tomada como fonte (Haguete, 1987), pois, como lembra Ferréz (2006), ninguém é inocente em São Paulo, e o deslocamento realizado para a pesquisa, dos bairros centrais a bairros mais distantes, como Jd. Ângela e Jd. S. Luís, realçava as diferenças da experiência de cidade vivida pelos pesquisadores naquela nova realidade, estabelecendo de imediato os parâmetros da investigação - éramos estrangeiros. ${ }^{1}$

O desafio de se debruçar sobre uma realidade social complexa, tão próxima geograficamente, mas tão distante social e simbolicamente, colocou em questão a bagagem que levávamos.

As visitas e as entrevistas feitas com diversas pessoas da periferia me permitiram, além de conhecer mais a realidade que engloba a maioria da população brasileira, quebrar um estereótipo muito forte: o do jovem da periferia acomodado e alienado com a sua situação atual. (P., 18 anos, pesquisadora)

O desconhecimento que tínhamos daquela realidade instigava o preconceito e a estereotipia. O reconhecimento da distância presente permitia constatar a barreira a ser enfrentada; ultrapassá-la tornou-se parte do desafio. Queríamos não apenas denunciar o preço que a sociedade paga pela segregação e fragmentação social, mas também encontrar a porção afirmativa dos desfavorecidos. Buscávamos não guardar destes jovens uma visão que, paradoxalmente, viesse a estigmatizá-los como vítimas e produtos deteriorados de um sistema perverso e produtor de desigualdade e de marginalização social, descrevendo-os em sua impotência e fragilidade social. Buscávamos encontrar a porção afirmativa que acreditávamos subsistir em seu discurso e ação, permitindo enunciá-los como sujeitos, na acepção plena do termo, ao serem vistos como protagonistas da história que foram capazes de construir, agentes capazes de reagir de diferentes modos às condições (favoráveis ou desfavoráveis) de sua realidade, conforme suas aspirações e recursos.

Certeau (1990/2012) tornou-se uma referência importante para a pesquisa pela visão que oferece do sujeito anônimo como agente ativo, alguém capaz de intervir com astúcia e criatividade em sua realidade cotidiana, explorando as lacunas de liberdade de que dispõe, diante das desiguais forças sociais que se organizam no espaço urbano. $\mathrm{O}$ autor propõe investigar o que chama de cultura ordinária (não no sentido de simplório, mas sim do universo tido como popular ou comum, próprio do Zé Ninguém), anônima do ponto de vista exterior à rede de relações locais, que utiliza recursos linguísticos como instrumentos de uma ação cotidiana, distante dos meios de comunicação tradicionais; que age criativa e coletivamente na construção e transformação de sua realidade, permitindo assim a construção de uma imagem afirmativa de homens e mulheres anônimos na cena urbana paulistana. ${ }^{2}$ 
Como estratégia de investigação, além da observação participante, foram realizadas conversas (Spink, 2008) com jovens e educadores da região (16 jovens e 13 educadores e gestores sociais), visitas a organizações locais voltadas à formação de jovens (5), uso de diário de campo como forma de registro dos dados coletados, pesquisas sobre demais organizações com este perfil, na região (3), bem como uma pesquisa bibliográfica sobre violência, vulnerabilidade, condição juvenil desfavorecida, espaço urbano de periferia na cidade de São Paulo e região sul, em particular, e os desafios de intervenção neste universo.

Diante da complexidade do tema da vulnerabilidade social na região estudada, foi possível estabelecer uma articulação inicial entre estes elementos, a partir dos dados que serão aqui apresentados, em favor da construção de um recorte sobre a condição de vida nos bairros de M’Boi Mirim e, em particular, de sua população juvenil. Trata-se, portanto, de um recorte introdutório sobre a realidade da juventude local, a partir de seus hábitos, fluxos, percepções e aspirações, tendo clara a necessidade de posteriores investigações que permitam o aprofundamento dos aspectos aqui levantados.

\section{A situação de risco nos bairros de M'Boi Mirim}

Vulnerabilidade é um campo de pesquisa que vem sendo explorado nas últimas décadas por várias vertentes das ciências humanas, na busca da compreensão e alerta quanto às dimensões de fragilidade social que incidem sobre populações desfavorecidas ou em condições sociais merecedoras de atenção dos poderes públicos. Permitiu, por exemplo, no que diz respeito aos trabalhos sobre infância e adolescência, não mais trabalhar com a noção de carência e de menor carente, em voga na década de 1970 (Feltran, 2011, p. 195), que embutia uma perspectiva individualizante e de simplificação psicológica, dando lugar a um viés mais complexo e social, que visa compreender a condição dos sujeitos em risco no cenário urbano. Spink faz o alerta sobre o risco de tomar a vulnerabilidade como condição própria de pessoas, quando não articuladas a contextos sociais que incide sobre estes e, para tanto, considera as vulnerabilidades sob três recortes: materiais, institucionais e sociais, que compõem as várias dimensões das vulnerabilidades urbanas (Spink, 2014), tal como encontramos na região de M’Boi, descrita adiante.

Kowarick, um dos autores que trabalham neste campo, aponta a dimensão plural da vulnerabilidade a partir de sua perspectiva socioeconômica e civil, considerando aí tanto os direitos sociais básicos de cidadania - trabalho, saúde, saneamento, educação e outros -, quanto a integridade física (e simbólica), ameaçada pela problemática da violência (Kowarick, 2009, p. 19). Tanto ele como outros autores destacam a importância e a prevalência que o tema da moradia e da ocupação espacial possui para a cidadania, no plano sociopolítico (Caldeira, 2000), e para a realidade simbólica, no plano psicossocial (Broide, 2010; Endo, 2005).

Cenário para a sociabilidade primária, a moradia é a condição primeira de cidadania, a partir da esfera doméstica, referência a partir da qual os sujeitos constroem seus planos e projetos de vida (Kowarick, 2009, p. 19). Consequentemente, morar num bairro desassistido de recursos públicos e precário quanto às oportunidades oferecidas pela multiplicidade de equipamentos de uma grande cidade já é, por si só, um forte indicador de propensão à condição de vulnerabilidade social. 
Jardim Ângela e Jardim São Luís compõem o distrito de M’Boi Mirim, situado no mapa da cidade à esquerda da represa de Guarapiranga, que neste início de século faz cem anos de existência. A região de M'Boi serviu desde o século XIX como polo produtor de alimentos e de material para a construção, recursos absorvidos pela capital paulista, de acordo com seu processo de urbanização e o desenvolvimento desta. Até 1936, pertencia ao município de Santo Amaro, que deixou de existir ao ser incorporado a São Paulo, em razão do aeroporto que ali fora recém-inaugurado, sendo então incorporado à capital (Prefeitura de São Paulo, 2014). Naquele início do século XX, diante da especulação imobiliária promovida pelas multinacionais que aqui atuavam - Companhia Light and Power e Companhia City - e com a anuência e apoio do poder público local, ocorreu o represamento da Guarapiranga (Endo, 2005; França, 2000; Santos, 2005, 2009), que se tornaria uma das principais fontes hídricas da capital, demarcando o território de modo inequívoco e irreversível.

A vocação da região como provedora de recursos para o Município de São Paulo se consolidava em cada uma destas etapas de sua ocupação, conforme se impunham as demandas da metrópole. A partir da década de 1950 e mais intensamente nas décadas de 1980 e 1990, houve uma aceleração desordenada da ocupação da região, sem qualquer diretriz do poder público e apoio de seus serviços. Fruto do processo de industrialização pelo qual a capital passava, um largo contingente populacional viu-se atraído pela possibilidade de acesso à casa própria, diante da especulação imobiliária que ocorria em toda a capital e promovia o afastamento daqueles que possuíam menos recursos para moradia.

A distância do poder público na região tornava a ocupação local irregular, mas, por isso mesmo, esta se mostrava menos exigente e menos onerosa e, portanto, mais acessível à população de baixa renda que servia de mão de obra para a indústria e serviços da cidade (Kowarick, 2009, p. 21). Criava-se, assim, um círculo vicioso de irregularidade, pois, ao não terem seus direitos sociais assistidos pelo poder público, a população de baixa renda se via premida a optar por uma condição de moradia irregular, bem como pela constituição de arranjos sociais paralelos (para acesso a fontes de renda e a necessidades básicas, como luz e água) à formalização que se instaurava no espaço urbano privilegiado da cidade.

M’Boi configurou-se, nas últimas décadas, como bairro dormitório, exigindo da população que ali se estabeleceu longos deslocamentos diários, em razão do trabalho oferecido nas regiões centrais da cidade. O bairro de Santo Amaro tornou-se a principal referência de serviços, comércio e mercado de trabalho para os novos moradores de M’Boi; mas seu acesso dependia e ainda depende das poucas vias que permitem contornar a represa. Um grande contingente populacional passou a se locomover pelas sobrecarregadas e concêntricas vias de acesso, que se afunilam como uma espinha de peixe, com vias locais escoando na principal, Estrada de M’Boi e Guarapiranga, sobrecarregadas na função de ligação com a região de Santo Amaro.

A ocupação do distrito ocorreu, em geral, no sentido do centro para a periferia da cidade: Jardim São Luís foi ocupado antes do Jardim Ângela, cuja porção mais afastada do centro - "o fundão", que chega à divisa da capital com Itapecerica da Serra - dispõe de menos estrutura e equipamentos públicos. Com uma população de 563.305 habitantes (Prefeitura), dividida equitativamente entre os dois bairros (267.871 no Jardim São Luís e 295.434 no Jardim Ângela), a região tem mais habitantes do que várias capitais brasileiras (como Cuiabá, Florianópolis e Vitória, além de outras), mas não possui equipamentos públicos para atender este contingente populacional. Ambos os bairros estão entre aqueles 
que possuem IDH (Índice de Desenvolvimento Humano) mais baixo da cidade: 0,750 e 0,798, respectivamente; para se ter uma ideia, os índices de Moema, Pinheiros e Freguesia do Ó são 0,961, 0,960 e 0,850.

A população juvenil, particularmente susceptível às vicissitudes da realidade local e, portanto, mais propensa ao risco diante das condições de vulnerabilidade enfrentadas, vive a precariedade do bairro, o que fica indicado pelo IDC (índice de composto juvenil: considera as taxas de homicídio, gestação adolescente, evasão escolar, mobilidade e lazer; Bousquat \& Cohn, 2003) dos dois bairros. Numa escala de o a 1, Jd. São Luís e Jardim Ângela encontram-se nas posições $79^{\mathrm{a}}$ e $94^{\mathrm{a}}$ entre os 96 distritos da Capital, com índices de 0,18 e 0,25. Como referência, bairros como Jardim Paulista e Moema, com os índices mais elevados da cidade, chegam a 0,78 e 0,77 , respectivamente. São dados dramáticos quando se observa a violência vivida pela juventude local: o número de óbitos juvenis (15 a 29 anos; 7,96 por cem mil no Jardim Ângela e 9,06 no Jardim São Luís; transposição para base cem mil para comparação. Nossa São Paulo, 2014) são superiores aos índices de países em conflito armado, como Iraque e Afeganistão (entre 8 e 9, aproximadamente, tendo em vista a dificuldade de acesso aos dados, em 2012; Escritório das Nações Unidas sobre Drogas e Crime - UNODC, 2013).

A violência no Jardim Ângela, em particular, ganhou visibilidade em 1996, quando a região foi apontada pela ONU como "a mais violenta do mundo", marcando de modo inequívoco o imaginário local. Se hoje deixou este posto, os índices não deixaram de ser alarmantes. Vale destacar que a violência na periferia paulistana tem cor, conforme a lógica de diversos territórios brasileiros: hoje, no país, entre cada jovem branco, há 12 jovens negros vítimas de homicídio (Waiselfisz, 2014).

Em contrapartida, a população local, com sua história recente, construiu uma tradição de lutas sociais e reivindicações sociais por melhorias, protagonizada pela for mação de associações locais que ganharam força nas três últimas décadas do século passado. Ainda que não se mostrem nem homogêneas quanto aos perfis, nem de todo convergentes quanto a seus objetivos e perspectivas, estas organizações vêm logrando avanços nas condições de vida local e oportunidades para a formação de jovens moradores da região.

\section{Dois lados do rio}

Na primeira visita que realizei à região, no final de uma primeira conversa com uma jovem moradora, vi-me diante de uma situação inusitada. Seguindo orientações dos contatos locais que fiz, fui acompanhado até o ponto de ônibus pela jovem negra, naquele fim de tarde, para que ela me oferecesse segurança. $\mathrm{O}$ pedaço ${ }^{3}$ onde estávamos era densamente ocupado por habitações precárias ou autoconstruídas e eu não tinha qualquer conhecimento a respeito daquele lugar; além disso, nenhum de seus moradores tinha registro sobre a minha pessoa. Havia uma inversão de posições instaurada: naquele bairro, eu, homem branco, morador de bairros da cidade centrais e mais assistidos, dependia da companhia de uma jovem negra da periferia para minha segurança - física ou simbólica.

Depois de algumas visitas à região, fui ganhando familiaridade e constatei a possibilidade de transitar desacompanhado; a situação inicial, porém, fora suficiente para marcar minha condição de pesquisador naquele pedaço. Denunciava quem era o estrangeiro por ali e quem tinha respaldo (social, segundo as redes de relações locais) para oferecer segurança. 
A inversão, aliás, tornava presente a versão: os moradores locais, defasados quanto às condições de vida oferecidas por seus bairros em relação às outras regiões da cidade, impunham ao recém chegado uma condição semelhante àquela que experimentavam cotidianamente, ao transitarem fora de seu pedaço em busca de sustento e inscrição social; como população desfavorecida, experimentavam a condição de excluídos nos bairros centrais da cidade, com melhores condições de infraestrutura pública e de serviços. Eu tinha a possibilidade, no estranhamento vivido como pesquisador, de entender como era viver a condição de estrangeiro em sua própria cidade, sem o amparo dos códigos sociais que sustentassem meu pertencimento ao meio.

A partir desta constatação, foi possível notar o peso simbólico que o rio adquire, entre seus moradores, ao separar o bairro (M’Boi Mirim e Capão Redondo, particularmente) da "cidade" (Santo Amaro e demais bairros centrais), como margens distantes entre realidades desiguais de uma mesma cidade. As fronteiras da realidade local, Jardim Ângela e Jardim São Luís, estão assim marcadas, no imaginário local, pelo rio Pinheiros e aquilo que ele representa. Capão e Ângela são referências importantes para muitos moradores, funcionando como insígnias simbólicas, tomadas como referências identitárias. Porém, as fronteiras entre estes bairros, Ângela, São Luís e também Capão Redondo, são tênues e imprecisas no imaginário local (o que nos levou a incluir depoimentos também destes moradores, quando se referiam a temas convergentes para os moradores do distrito de M'Boi). O principal organizador do território, portanto, não é a definição do distrito propriamente, mas o rio (e a represa) que, como divisor de águas em relação a Santo Amaro e seus equipamentos públicos e privados, marca a fronteira entre o que se passa do lado de lá e do lado de cá das águas turvas de mais este ente esquecido na cidade: "Aqui, até a estátua do Borba Gato está de costas para nós” (participante do Fórum Zona Sul, Jd. Ângela), sintetiza um morador. Outro descreve a diferença: "Não tem um teatro, não tem um cinema, não tem um ginásio, não tem nada. Essa região é desprovida de tudo. Tudo o que temos, inclusive, é pra lá: em Santo Amaro” (O, 42 anos, educador, Jd. Ângela). A noção de bairro de periferia é clara, considerando-se a desigual distribuição de recursos que os dois lados do rio apresentam; o cotidiano de seus moradores também está marcado pelas diferenças de oportunidades de que dispõem.

Campo Limpo é outra parada. Apesar de sua fronteira ser igualmente imprecisa para muitos daqueles que moram em suas cercanias (confundindo-se por vezes com o bairro Capão Redondo, aliás), é referência de um bairro com mais recursos e assistência do poder público, contando com maior reconhecimento social e atribuição de valor entre seus moradores. Capão Redondo, por sua vez, apesar de sua proximidade em relação a Campo Limpo e da presença do metrô em sua borda, é considerado um bairro menos assistido em relação a este e, neste sentido, mais próximo do Jd. Ângela e de suas dificuldades, no discurso de seus moradores.

Como visão geral da condição de vida local, os moradores do M’Boi consideram o afastamento do Estado como um dos principais fatores responsáveis pela precariedade da região, na medida em que responde pela maioria dos problemas enfrentados, que são: a precariedade da habitação, a ausência de saneamento básico em boa parte da região e seus efeitos nas condições de saúde, a dificuldade de acesso a equipamentos de saúde, o desajuste entre empregos disponíveis e aspirações profissionais da população, a dificuldade de deslocamento, a falta de opções de lazer e a inadequação das escolas à cultura local. A polícia é um dos equipamentos públicos mais atuantes na região (assim como a escola), mas, ao invés de zelar pela segurança, é apontada como principal fator responsável pelo incremento da violência local. 
Sobre o acesso ao mercado de trabalho, apesar de perceberem a melhoria na oferta de emprego na região na última década, a situação não é vista como promissora para o público jovem, pois as ofertas disponíveis não condizem com os anseios deste segmento. Os jovens entrevistados, de modo geral, não buscam apenas um emprego, mas atividades com as quais se identifiquem e que lhes tragam uma perspectiva de futuro, conforme seu ideário; querem perceber-se respeitados e reconhecidos pelo que realizam - "quando eu trabalhava com carteira assinada, me tomava muito tempo, com stress e o patrão que não presta atenção no empregado. Então, com carteira assinada eu não quero mais” (D, 30 anos, Capão). Ou ainda:

\begin{abstract}
Se você tiver 16 anos e for no CAT, você consegue uma oportunidade de emprego, mas não é boa. Ai você vai parar em fast-food, ou shopping. E é muito maçante uma pessoa que tem 16 anos e que ainda não terminou os estudos, trabalhar num fast-food, de segunda a segunda, quase 10 horas diárias e você recebe um salário mínimo. Não dá pra você se sustentar, não dá pra você ajudar na sua casa, quase não dá para você fazer suas coisas, aí você acaba parando de estudar pra poder ter um dinheiro, porque você precisa de um dinheiro, porque sua mãe não pode te dar as coisas que você precisa. Aí você para de estudar, você não faz curso. (L., 18 anos, Capão/Ângela)
\end{abstract}

A situação atual apresenta ganhos significativos em relação a décadas passadas, como a diminuição da miséria e a possibilidade de acesso a um padrão de consumo popular. Porém, e talvez por isso mesmo, os anseios juvenis apontam para expectativas distintas das atuais possibilidades encontradas, tanto em relação ao trabalho, quanto em relação ao consumo: "O jovem está num outro momento, ele não é mais o jovem da miséria, que não tinha arroz e feijão pra comer. Com 13 anos em diante, o jovem já começa a ter essa identidade” (O, 42 anos, educador, Ângela). Neste sentido, portanto, não basta sobreviver, é preciso existir: "É a ostentação de você querer um tênis da hora, você querer um cordão de ouro. Porque muitos aqui têm um cordão, mas não é de ouro. Então, é o querer..." (D, 30 anos, Capão).

Num contexto social fortemente urbanizado e marcado pelo advento da globalização - como ocorre em São Paulo - o acesso aos bens de consumo divulgados pelos meios de comunicação tornou-se condição de pertinência e reconhecimento social (Lipovetsky, 2007). O consumo tornou-se um meio de acesso aos recursos simbólicos fomentados do lado de lá do rio, bem como condição de reconhecimento entre pares, conforme os códigos localmente estabelecidos (o que condiz com a análise realizada por Feltran em Sapopemba, zona leste da cidade - 2011, p. 169). Os jovens entrevistados da região de M’Boi almejam conquistar status em seu meio, bem como ter recursos (simbólicos e materiais) para poder transitar pela cidade e ultrapassar o rio, sem perder seu lugar de pertinência. Demonstram, aliás, ter orgulho do bairro onde vivem e vontade de lá seguir morando - "Eu mesmo não penso em sair daqui, falo pra minha mãe que quando crescer, ser alguém na vida, eu vou continuar morando aqui. É aqui que eu vou ficar" (T, 20 anos, Capão/Ângela).

Os anseios pelos bens de consumo trazem desafios para os equipamentos locais voltados à educação. Para os programas extracurriculares, este anseio juvenil limita diretamente sua disponibilidade de desenvolvimento de repertórios, nas atividades promovidas por organizações locais; "o jovem topa fazer cursos, mas o que ele ganha com isso, 'cadê a bolsa'? Eu quero alguma coisa. Eu preciso comprar meu tênis!” (O, 42 anos, educador, Ângela). Consequentemente, a urgência com que tal anseio é vivido restringe as possibilidades de formação dos jovens, que, com frequência, buscam meios mais rápidos para o acesso aos 
bens almejados. A escola formal, por sua vez, mostra-se muitas vezes distante das demandas juvenis, não só por não conseguir funcionar como mediadora entre os jovens e suas ambições imediatas, mas também por oferecer acesso a um saber que é visto como distante de sua experiência cotidiana, não chegando a ser valorizada como um bem em si (Carvalho, 2013) - “... nunca foi um interesse para mim (o estudo), no último ano passei empurrada, sem saber nada" (D, 30 anos, Capão). Como resultado, a escola acaba não conseguindo servir como instrumento de inclusão social:

A escola pública... não consegue segurar o jovem na escola.... As estatísticas mostram que o analfabetismo diminuiu, mas nós temos um monte de analfabetos funcionais. Os nossos jovens não conseguem passar numa prova da ETEC, eles não conseguem passar numa prova da PRONATEC disponibilizada no sistema. (O, 42 anos, educador, Ângela)

As escolas locais tornam-se assim alvo de intensas e variadas queixas, em função da insuficiência de equipamentos, da falta de adequação de sua estrutura à realidade local e da dificuldade de diálogo tanto com a comunidade, quanto com os demais equipamentos (públicos ou não) que atuam junto ao mesmo segmento infanto-juvenil. Por serem alvo de intensas expectativas de famílias e jovens em favor do desenvolvimento destes, permitindo-lhes ultrapassar a barreira do rio, as escolas acabam sendo responsabilizadas pelo insucesso vivido. Ao invés de combater a segregação e a desigualdade social, são vistas elas próprias como as responsáveis por sua promoção:

são poucos projetos de assistência social que aceitam meninos de liberdade assistida. Nós temos a seguinte exclusão: os meninos de liberdade assistida e deficientes, mentais e físicos. Tanto as escolas quanto a maioria dos projetos sociais não aceitam, dizem que não têm vaga. (O, 42 anos, educador, Ângela)

Premidas por uma política de desempenho (meritocrática, pautada em rankings que estabelecem premiações conforme os resultados obtidos por seus alunos), as escolas públicas da região por vezes também contribuem para a evasão escolar de uma parcela de jovens que encontra maior dificuldade de corresponder às demandas do sistema de ensino. São jovens que não conseguem se identificar com a proposta de desenvolvimento pedagógico, seja pela dificuldade diante do próprio aprendizado, distante do campo de referências da realidade local, seja pelo conflito entre suas aspirações e as exigências do meio formal e informal, aspectos que frequentemente interligados.

Por outro lado, nota-se a idealização do papel da instituição escolar, tendo em vista a expectativa de "segurar os jovens nas escolas", como expressam vários entrevistados, como se fosse ela capaz de transformar, por conta própria, a realidade local. Apesar da presença da instituição escolar na região, as escolas tornam-se, em razão da dificuldade para responder às demandas locais, no olhar de muitos moradores, mais um sinal de descaso do poder público.

Nas visitas realizadas às organizações locais, voltadas à educação formal ou complementar (escolas, centros de juventude e de formação artística), foi possível perceber o recorrente compromisso de seus agentes com os objetivos estabelecidos em cada organização e a disposição para sua realização, apesar da constatada heterogeneidade de propostas e das políticas de gestão praticadas. Porém, percebe-se que a articulação de ações entre pares locais é frágil ou incipiente, o que vem limitar o potencial de ação de cada equipamento em sua realidade específica e do conjunto de organizações, com um todo, no território. 
Diante da dificuldade dos equipamentos de educação em lidar com os anseios juvenis locais, bem como da falta das oportunidades de lazer oferecidas na região, da precariedade de recursos públicos promotores do bem-estar social e da dificuldade de acesso a outras regiões da cidade mais assistidas, a juventude local torna-se alvo das tensões sociais ali vividas. Ou seja, o cenário, somado à urgência das demandas juvenis, torna os jovens susceptíveis à expansão do mundo do crime, fenômeno que vem ocorrendo nas regiões menos assistidas da cidade, nestas últimas décadas (Feltran, 2011), em razão da possibilidade de lazer e fruição (uso de drogas), do anseio de acesso rápido a bens de consumo e do status social entre pares - "ganhei muito dinheiro no tráfico, mas dinheiro sujo, que vem fácil, vai fácil. Comprei moto... mas foi rápido, o que veio, foi” (A, 21 anos, Capão). Esta realidade caracteriza o aspecto mais agudo da condição de vulnerabilidade social dos jovens moradores da região.

A situação local, no entanto, não é fruto somente das dificuldades específicas da população local e de sua ocupação do território. O bairro também serve a interesses que vigoram nas regiões mais favorecidas da cidade, o que vem somar-se às dificuldades ali enfrentadas. Exemplo disto é o deslocamento ocorrido em 2013, conforme depoimento de agentes locais, de uma população em clara condição de fragilidade social, em função da política de higiene que era na época praticada pela municipalidade paulistana: "Próximo daqui nós temos uma cracolândia, que funciona 24 horas, e surgiu faz algum tempo, mas se intensificou depois do movimento de higienização em $S P$ ” (O, 42 anos, educador, Ângela). Neste ponto, a região funciona como cidade invisível, quando se presta à negação e expiação de problemas que inquietam a cidade como um todo. Questões não resolvidas podem ser esquecidas pelos meios de comunicação e habitantes dos bairros centrais da cidade, ao serem deslocadas para bairros periféricos (o outro lado do rio) e permanecerem circunscritas ali. Como se sabe, a corrente se rompe no elo mais fraco.

A violência que incide na região, portanto, é resultado de um conjunto de fatores internos e externos ao distrito. Atualmente, é a principal queixa de seus moradores, que entendem sua realidade a partir do sentido atribuído à localização geográfica do bairro: " $a$ gente mesmo do lado de cá, da Zona Sul, é um pouco esquecido, vocês não, vocês já tem atenção, tem mais lazer do que a gente aqui” (L, 17 anos, Ângela). Tal esquecimento é visto, por exemplo, na precariedade dos serviços públicos que corroboram para a falta de segurança dos moradores, como a falta de iluminação - "onde eu moro agora não tem isso, a minha rua é deserta, chega 10, 11 horas da noite, já tá tudo escuro, você corre risco de ser assaltada” (A, 15 anos, Ângela); ou pela arbitrariedade da ação da polícia na região que, segundo os entrevistados, é deliberadamente discriminatória, ultrapassa os limites legais do uso da violência - "Dá pra gente ver que é autoridade, que, querendo ou não, bom ou ruim, eles tão no poder. Mas não precisa de toda essa ignorância...” (A, 15 anos, Ângela). A juventude negra, por sua vez, é o segmento mais vulnerável, pois, como disse um jovem entrevistado, a pior situação é aquela dos "três Ps, ser preto, pobre e periférico" (L, 18 anos, Capão); este é o segmento mais exposto à violência aleatória que acompanha o cotidiano da região, como apontam vários relatos recolhidos:

... achou que a gente era ladrão, porque quando eu tomei os tiros, você sabe que ladrão chega, mata e vai embora, não quer saber de nada, né? Agora os caras que deram tiro em mim não, os caras que deram tiro em mim tavam dando tiro $m$ mim e recolhendo as cápsulas pra não saber quem foi, recolhendo os vestígios. Por isso que pra mim foi polícia, se fosse ladrão ia deixar tudo lá. (L, 17, Capão) 
Histórias como estas são recorrentes e atestam a invisibilidade da violência cotidiana vivida por muitos jovens paulistanos, que enfrentam constantemente o medo, a ameaça e os efeitos de sua sorte. Não é de estranhar, então, a existência de um fenômeno circular de violência entre polícia e população local - "o pessoal também tá muito agressivo com a polícia. Você viu aquilo, policial apanhando das pessoas?!”(V, 15 anos, Ângela) - mostrando a gravidade de um problema que se produz num espaço desassistido de recursos públicos capazes de evitar os excessos ali perpetrados.

A violência, em seu limite, é uma experiência sem sentido, que tende a reproduzir-se (psiquicamente ou como fenômeno social) quando não encontra dispositivos sociais voltados para sua expressão e significação (Endo, 2005). Caldeira, ao se debruçar sobre a questão da violência em São Paulo, mostra que a questão da violência na cidade de São Paulo não é uma questão puramente local, pois faz parte do ciclo de violência que identifica, formado pela relação direta entre desigualdade socioeconômica e segregação espacial nos territórios da cidade, diferenciando regiões mais ou menos assistidas por recursos públicos (como iluminação, transporte, saneamento, policiamento) e por recursos privados acessíveis aos segmentos socioeconomicamente privilegiados (como saúde, educação e ofertas de trabalho qualificado). Decorre daí que a disparidade de oportunidades e de recursos entre uns e outros produz tensões e conflitos, culminando em crimes e práticas violentas entre os vários atores envolvidos. A população busca respostas para os conflitos enfrentados e, diante de um "sistema judiciário ineficaz", que pratica a justiça "como um privilégio da elite", os dilemas tendem a ser personalizados, ao se considerar o crime e a prática de atividades ilícitas fruto de condutas antissociais desviantes, a serem enfrentadas por meio da punição violenta socialmente legitimada (Caldeira, 2000, p. 375).

A discussão é extensa, mas vale como referência para marcar a complexidade e abrangência da questão. Faz ver que não se trata de problemas meramente locais, que dizem respeito especificamente à fragilidade da região e à vulnerabilidade de sua população, mas partem de um quadro de desequilíbrio social vigente na cidade (e no país), conjugado à disjunção do projeto de democracia nacional ante o desrespeito constante à equidade dos direitos civis dos cidadãos - distribuição desigual da violência e do direito a ter direitos, como mostra Caldeira em seu trabalho. ${ }^{4}$

\section{Considerações finais}

É clara a condição de vulnerabilidade da juventude local em vários âmbitos de sua realidade. Apesar de serem apontadas melhorias na região na última década, como a maior oferta de trabalho nas localidades mais antigas e próximas a Santo Amaro, a oferta de oportunidades de formação promovidas por ações voltadas à educação complementar, a diminuição da miséria e a possibilidade de acesso ao consumo popular, essas conquistas não ocorrem de modo homogêneo, nem são suficientes para atenuar significativamente as dificuldades e ameaças vividas pela população local. Percebe-se, em contrapartida, a precariedade do distrito de M'Boi Mirim em diversos aspectos da realidade local: a heterogeneidade ou inadequação das oportunidades de trabalho diante das aspirações da juventude local, a insuficiência das possibilidades de formação complementar, a precariedade dos equipamentos públicos (como os de atenção à saúde), a inadequação dos equipamentos de educação formal à cultura e demandas locais, a falta de oportunidades de lazer para as 
diferentes faixas etárias, a dificuldade de deslocamento (tanto na região quanto para fora dela), a violência policial e a falta de segurança da população, bem como a própria invisibilidade da região, esquecida ou vista sob um olhar estereotipado. Tal realidade torna-se, consequentemente, propícia a arranjos informais capazes de instaurar uma ordem social e leis próprias, refratárias ao poder público, e que acabam por fortalecer ou aumentar a distância entre as duas margens do rio.

Os jovens, por sua mobilidade e condição social estratégica, mostram-se particularmente premidos pelos problemas da região. Reagem ativamente conforme os recursos que estão a seu alcance, ao formular projetos de vida (idealizados ou não) a partir da participação em programas sociais oferecidos na região pelo poder público ou por organizações sociais, ou mesmo da participação em organizações do poder paralelo, promotoras de práticas ilícitas, à revelia das forças institucionalmente legitimadas pelo poder público.

Ainda que a dicotomia entre lícito e ilícito seja uma referência clara no imaginário social local, a fronteira entre ambos se mostra menos clara e definida do que de início se supunha. O envolvimento com atividades ilícitas não é um caminho sem volta, ainda que tais experiências tragam dificuldade para a chamada reintegração social (aos universos reconhecidamente percebidos como legítimos pelos vários segmentos sociais da população paulistana) conforme o grau de envolvimento do jovem com elas. Perder a primariedade, ter ficha na polícia e viver uma experiência prisional são marcos que definem socialmente um maior envolvimento com o mundo do crime e, consequentemente, maior dificuldade de acesso aos espaços e recursos lícitos acessíveis. Ainda assim, é recorrente a formação de vínculos (de amizade, solidariedade ou de troca) entre jovens com trajetórias distintas, entre o lícito e o ilícito, bem como a composição de famílias que possuem jovens de ambos os perfis. Portanto, a dicotomia entre trabalhadores e bandidos serve ao imaginário local como referência simbólica organizadora dos parâmetros para a orientação dos projetos de vida que constroem, mas não se efetiva como configuração de universos distintos, com valores e normas sociais incompatíveis entre si (Feltran, 2011).

A despeito das adversidades, ou talvez, sobretudo em decorrência delas, percebe-se a postura proativa dos moradores da região na construção de dispositivos sociais que funcionem como anteparo e lastro societário frente às dificuldades enfrentadas. A disposição para a formação de laços de solidariedade entre pares é mostra disso: a ajuda mútua e cotidiana entre pares em torno de aspectos básicos da vida local, como alimentação, transporte ou financiamento de custos, opera como recorrente, versátil e consistente apoio entre os moradores da comunidade no enfrentamento de suas dificuldades cotidianas. Tal recurso chega a ser, até, a possibilidade de existência de muitos, quando se consideram, por exemplo, os arranjos necessários para a mediação de conflitos fatais entre jovens na disputa de poder e reconhecimento social do pedaço (sobre este último aspecto, ver Broide, 2010, pp. 74-114).

O vínculo de solidariedade, no entanto, não se dá de modo indiscriminado, entre todos, mas conforme os laços de identificação estabelecidos e as situações de contexto. São táticas de sobrevivência ou de existência para sujeitos - no sentido forte do termo - que reagem às condições precárias de um território menos assistido, táticas que operam como cálculo de força, astúcia imprevista criada a cada golpe, em cada situação, ante o domínio das forças de poder que, pela imposição ao mais fraco ou esquecimento do invisível, são determinantes nas vicissitudes locais (Certeau, 2012).

A juventude, protagonista nesse movimento de oposição às forças dominantes, é vítima da segregação social e da violência dos órgãos de segurança da região e vive essa 
condição de vulnerabilidade social como realidade cotidiana. Mas não se restringe à condição de vítima, pois reage a ela por meio de diferentes arranjos, que transformam a própria adversidade de sua condição na possibilidade de estruturação de uma vida possível, com recursos e oportunidades, o que pode ser visto na enunciação de projetos individuais de formação e de vida, na afirmação de apego e orgulho de um bairro que tem valor, apesar de todos os problemas que possui, na criação de espaços de lazer que permitem o convívio entre pares, a experiência societária e sexual, bem como o exercício da expressão simbólica dos dilemas e aspirações vividas - como é o caso do baile funk - na participação de organizações locais que operam na ilegalidade e instauram uma ordem social de que o Estado abriu mão, ou ainda, na possibilidade de estabelecer laços de cumplicidade e solidariedade entre pares, subvertendo a lógica do bem individual, tão característico do ideário capitalista, do qual todos participamos.

A intensidade e a amplitude da condição de vulnerabilidade social da juventude local estão, assim, acompanhadas por movimentos de reação frente às adversidades e de construção de caminhos alternativos que aspiram responder a demandas cotidianas e à realização dos anseios juvenis. A investigação da vulnerabilidade social da juventude na região, portanto, convoca à escuta de sua capacidade de reação aos riscos enfrentados, a fim de não tomar o jovem apenas como vítima, mas como sujeito agente, capaz de construir alternativas para a transformação de sua realidade, conforme as oportunidades que encontra em cada contexto.

\section{Notas}

$1 \mathrm{Na}$ construção do método de investigação, juntamente à formulação de Haguete, também foi utilizada a estratégia proposta por P. Spink (2008), do pesquisador conversador e a proposta etnográfica de investigação do "pedaço", que busca fazer a análise da experiência urbana a partir de seus atores, como "agentes que dinamizam suas esferas de realidade”, conforme propõe J. G. Magnani (2012, p. 19).

2 Perspectiva que se mostra próxima à proposta freudiana de dar escuta à fala do sujeito em sua singularidade, com a seguinte diferença: Certeau realça a posição do homem anônimo no jogo de forças desigual no tecido social, destacando a dimensão criativa de uma maioria marginal e silenciada que se enuncia por discursos anônimos (Certeau, 2012).

3 Pedaço aqui considerado como referência espacial, presença regular de seus membros e um código de reconhecimento e comunicação entre eles - Magnani, 2012.

4 Um interessante estudo sobre um grupo de jovens de classe média, que cultivava práticas transgressoras na década de 1970, e que recebia um tratamento diferenciado por parte da polícia e meios de comunicação, em relação a seus pares correspondentes das classes populares; para os primeiros, era uma experiência passageira, de rebeldia juvenil, para os demais, tratava-se de um divisor de águas que iria definir os desencaminhados a serem punidos e segregados (Silva, 2006). 


\section{Referências}

Bousquat, A. \& Cohn, A. (2003). A construção do Mapa da Juventude de São Paulo. Lua Nova, 60, 81-96.

Broide, J. (2010). Psicanálise nas situações sociais críticas. Violência, juventude e periferia: uma abordagem grupal. Curitiba: Juruá.

Caldeira, T. P. (2000). Cidade de muros: crime, segregação e cidadania em São Paulo. São Paulo: 34/Edusp.

Carvalho, J. S. (2013). Reflexões sobre educação, formação e esfera pública. Porto Alegre: Penso.

Certeau, M. (2012). A invenção do cotidiano: 1 Artes de fazer. Petrópolis, RJ: Vozes. (Original publicado em 1990)

Endo, P. C. (2005). A violência no coração da cidade: um estudo psicanalítico. São Paulo: Escutta/Fapesp.

Feltran, G. (2011). Fronteiras de tensão: política e violência nas periferias de São Paulo. São Paulo: Unesp/Cebrap.

Ferréz. (2006). Ninguém é inocente em São Paulo. Rio de Janeiro: Objetiva.

França, E. (Coord.). (2000). Guarapiranga: recuperação urbana e ambiental no município de São Paulo. São Paulo: M. Carrilho Arquitetos.

Haguete, T. M. F. (1987). Metodologias qualitativas na Sociologia. Petrópolis, RJ: Vozes. (Original publicado em 1987)

Kowarick, L. (2009). Viver em risco: sobre a vulnerabilidade socioeconômica e civil. São Paulo: Editora 34.

Lipovetsky, G. (2007). A felicidade paradoxal: ensaio sobre a sociedade de hiperconsumo. São Paulo: Companhia das Letras.

Magnani, J. G. C. (2012). De perto e de dentro: notas para uma etnografia urbana. Revista Brasileira de Ciências Sociais, 17(49), 11-29.

Rede Nossa São Paulo. (2014). Observatório Cidadão: indicadores de Homicídio Juvenil. Recuperado de http://www.redesocialdecidades.org.br/br/SP/sao-paulo/regiao/++jardimngela/homicidio-juvenil

Prefeitura de São Paulo. (2010). Subprefeitura de M’Boi Mirim. Histórico. Recuperado de http://www.prefeitura.sp.gov.br/cidade/secretarias/regionais/m boi mirim/historico/

Prefeitura de São Paulo (2014). Dados demográficos dos distritos pertencentes a subprefeitura. Recuperado de http://www.prefeitura.sp.gov.br/cidade/secretarias/regionais/subprefeituras/dados demograficos/index.php? $\mathrm{p}=12758$

Santos, M. (2005). O retorno do território. In OSAL: observatório Social de américa latina, 6(16), 25 1-261. Recuperado de < http://bibliotecavirtual.clacso.org.ar/ar/libros/osal/ osal16/D16Santos.pdf $>$

Santos M. (2009). Metrópole corporativa fragmentada: o caso de São Paulo (2a. ed.). São Paulo: Universidade de São Paulo. (Original publicado em 1990) 
UNODC. (2013). UNODC e Ministério da Justiça reúnem dados sobre tráfico de pessoas no Brasil e lançam nova metodologia de pesquisa. Recuperado de https://www.unodc. org/lpo-brazil/pt/frontpage/index.html

Waiselfisz, J. J. (2014). Mapa da Violência 2014: os jovens do Brasil. Brasília, DF: Secretaria Nacional da Juventude. Recuperado de http:///www.mapadaviolencia.org.br/ pdf2014/Mapa2014 JovensBrasil.pdf

Silva, E. M. (2006). Trajetórias violentas e origem social dos jovens: o caso da turma do Barão. In M. R. Costa \& E. M. Silva (Orgs.), Sociabilidade juvenil e cultura urbana (pp. 149-168). São Paulo: Educ.

Spink, P. (2008). O pesquisador conversador. Psicologia E Sociedade, 20(n. spe.), 70-77.

Spink, P. K. (2014). Bringing the horizon back in: the mid-range approach to Organizational Studies. Revista Brasileira de Estudos Organizacionais, 1(1), 1-26.

\section{TIAGO CORBISIER MATHEUS}

https://orcid.org/0000-0003-0430-2201

Pesquisador do Centro de Estudos em Administração Pública e Governo (CEAPG) da EAESP/FGV no tema de juventude, professor de Psicologia Social, psicanalista.

Endereço: FGV-EAESP - FGV. Av. 9 de Julho, 2029, $11^{\circ}$ andar Bela Vista 01313-902 - São Paulo/SP, Brasil.

E-mail: tiago.matheus@fgv.br

tmatheus@,uol.com.br

\begin{tabular}{|l|l|}
\hline Histórico & $\begin{array}{l}\text { Submissão: 24/7/2017 } \\
\text { Revisão: 14/08/2018 } \\
\text { Aceite: 30/10/2019 }\end{array}$ \\
\hline Financiamento & Não se aplica. \\
\hline $\begin{array}{l}\text { Consentimento de } \\
\text { uso de imagem }\end{array}$ & Não se aplica. \\
\hline
\end{tabular}

